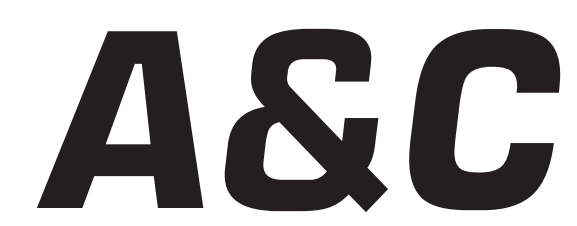

Revista de Direito Administrativo \& Constitucional

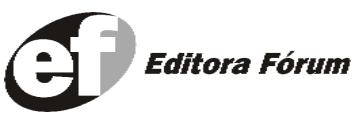

A\&C R. de Dir. Administrativo e Constitucional, Belo Horizonte, ano 6, n. 23, p. 1-253, jan./mar. 2006 


\section{A\&C REVISTA DE DIREITO ADMINISTRATIVO E CONSTITUCIONAL}

\section{IPDA}

Instituto Paranaense

de Direito Administrativo

Direção Geral

Romeu Felipe Bacellar Filho

Direção Editorial

Paulo Roberto Ferreira Motta

Direção Executiva

Emerson Gabardo

Conselho de Redação

Edgar Chiuratto Guimarães

Adriana da Costa Ricardo Schier

Célio Heitor Guimarães

Conselho Editorial

Adilson Abreu Dallari

Alice Gonzáles Borges

Carlos Ari Sundfeld

Carlos Ayres Britto

Carlos Delpiazzo

Cármen Lúcia Antunes Rocha

Celso Antônio Bandeira de Mello

Clèmerson Merlin Clève

Clóvis Beznos

Enrique Silva Cimma

Eros Roberto Grau

Fabrício Motta

Guilhermo Andrés Muñoz (in memoriam)

Jaime Rodríguez-Arana Muñoz

Jorge Luís Salomoni
José Carlos Abraão
José Eduardo Martins Cardoso

José Luís Said

José Mario Serrate Paz

Juan Pablo Cajarville Peruffo

Juarez Freitas

Julio Rodolfo Comadira

Luís Enrique Chase Plate

Lúcia Valle Figueiredo

Manoel de Oliveira Franco Sobrinho

(in memoriam)

Marçal Justen Filho

Marcelo Figueiredo

Márcio Cammarosano

Maria Cristina Cesar de Oliveira
Nelson Figueiredo

Odilon Borges Junior

Pascual Caiella

Paulo Eduardo Garrido Modesto

Paulo Henrique Blasi

Paulo Neves de Carvalho (in memoriam)

Paulo Ricardo Schier

Pedro Paulo de Almeida Dutra

Regina Maria Macedo Nery Ferrari

Rogério Gesta Leal

Rolando Pantoja Bauzá

Sérgio Ferraz

Valmir Pontes Filho

Yara Stropa

Weida Zancaner

\footnotetext{
A246 A\&C Revista de Direito Administrativo e Constitucional. ano 3, n. 11, jan./mar. 2003. Belo Horizonte: Fórum, 2003.

Trimestral

ano 1, n.1, 1999 até ano 2, n.10, 2002 publicada pela Editora Juruá em Curitiba

ISSN: 1516-3210

1. Direito Administrativo. 2. Direito Constitucional. I. Fórum.
}

CDD: 342 CDU: 33.342

(c) Editora Fórum Ltda. 2006

Todos os direitos reservados. É proibida a reprodução total ou parcial, de qualquer forma ou por qualquer meio eletrônico ou mecânico, inclusive através de processos xerográficos, de fotocópias ou de gravação, sem permissão por escrito do possuidor dos direitos de cópias (Lei $n^{\circ}$ 9.610, de 19.02.1998).

Editora Fórum Ltda

Av. Afonso Pena, 2770 - 15\%16ªndar - Funcionários

CEP 30130-007 - Belo Horizonte/MG - Brasil

Tel.: 08007043737

Internet: www.editoraforum.com.br

e-mail: editoraforum@editoraforum.com.br
Editor responsável: Luís Cláudio Rodrigues Ferreira Projeto gráfico e diagramação: Luis Alberto Pimenta Revisora: Olga M. A. Sousa

Pesquisa jurídica: Fátima Ribeiro - OAB/MG 74868

Bibliotecária: Nilcéia Lage de Medeiros

CRB 1545/MG 6a região

Os conceitos e opiniões expressas nos trabalhos assinados são de responsabilidade exclusiva de seus autores.

Impressa no Brasil / Printed in Brazil

Distribuída em todo Território Nacional 


\title{
Teoria geral da ordem jurídica internacional
}

\author{
Alexandre Coutinho Pagliarini \\ Membro do NUPECONST - Núcleo de Pesquisa em Direito Constitucional da UniBrasil. Mestre e \\ Doutor em Direito pela PUC/SP. Coordenador de Pós-Graduação e Professor da UniBrasil
}

Palavras-chave: Teoria geral da ordem jurídica internacional ; Organizações Internacionais; Teoria Geral do Estado; Direito Internacional Público; Personalidade Jurídica Internacional

Preliminarmente, deve-se firmar o entendimento de que o direito internacional, por impor atos de violência veiculados pela sanção, é dotado de inegável caráter jurídico, ou seja, nele se encontra o deôntico. Tanto a norma internacional costumeira quanto aquela introduzida por tratado são portadoras de obrigações, permissões e proibições, podendo-se identificar que, dado o fato de um Estado não cumprir o previsto na hipótese da norma internacional, deve-ser uma conseqüência consubstanciada numa sanção. Veja-se o seguinte exemplo referente a um delito por inobservância de norma costumeira de direito das gentes: suponha-se que uma hipotética CidadeEstado chamada Zubatão faça fronteira com a Cidade-Estado hipotética denominada Pasárgada. As centenas de indústrias estatais localizadas em Zubatão emitem, em conjunto, uma massa poluidora tão grande que provoca dois danos no território de Pasárgada: malefícios pulmonares identificados em 95\% das crianças e dos idosos de Pasárgada, e isto traz prejuízo àquele Estado visto que gasta dinheiro para tratar os enfermos pelo sistema de saúde pública; corrosão incorrigível nos centenários monumentos artísticos em pedra-sabão, localizados ao ar livre em diversos sítios daquela Cidade-Estado.

Existe a norma costumeira que diz que um Estado não pode causar prejuízo a outro por atitude ilícita. A partir dessa norma, dado o fato de Zubatão poluir Pasárgada, causando-lhe prejuízo material e malefícios à saúde de seu povo, deve-ser a aplicação de sanção.

Veja-se, agora, um exemplo abstraído de uma hipótese advinda de norma posta por tratado: os Estados X e Y, há duas décadas, puseram fim aos atos beligerantes que se sucediam, firmando tratado que prescrevia ao Estado X a obrigação de retirar suas tropas da área Y' do Estado Y. Dias atrás, o novo governo do Estado X viola aquele tratado, instalando naquela área 
Y' um pequeno contingente de membros de seu exército. Assim, verificado o fato de o Estado X haver instalado no território proibido o contingente militar, deveser a sanção que, neste caso, se consubstanciará na represália ou na própria guerra.

As regras internacionais - mesmo que não haja no mundo a mesma caracterização de unicidade institucionalizada verificável no direito nacional — são normas jurídicas que impõem a represália ou até a guerra, no caso de violação de seus preceitos hipotéticos e dependendo do grau da violação. Com tais dizeres, quer-se afirmar que a inobservância da regra relacional contida no antecedente da norma internacional implica uma conseqüência, quer dizer, uma sanção. Desta maneira, não há como se vislumbrar a menor hipótese de se deixar de ver a ordem jurídica internacional como sistema normativo veiculador de um dever-ser, razão pela qual a fórmula lógica da norma jurídica se amolda também ao direito internacional:

$\mathbf{D}[(\mathbf{p} \rightarrow \mathbf{q}) .(\mathbf{q} \rightarrow \mathbf{S})$ ]; leia-se: "deve-ser" $(D)$ que, dado o fato " $p$ ", então "deve-ser" a conduta " $q$ " (se " $p$ " então " $q$ "), $e$, não se observando a conduta "q", então "deve-ser" a "sanção".

Se é verdade que a produção do complexo doméstico de normas se dá dentro de um contexto fechado, burocratizado e absolutamente institucionalizado que é o Estado soberano, não é verdadeira a mesma assertiva quanto à produção do complexo de normas internacionais, fato esse que fez com que Kelsen comparasse o direito internacional ao direito estatal dos tempos primitivos, época em que se praticava a vingança privada. ${ }^{1}$

Ao contrário do que se vê no direito interno de um Estado, de fato não se constata no direito internacional a existência (i) de um Estado mundial institucionalizado e fechado, (ii) de um órgão legislativo mundial produtor de normas válidas, a se verem eficazes perante todos os Estados soberanos do planeta, (iii) de um tribunal global cujas decisões façam res iudicata perante todos sujeitos de direito internacional público, e, por fim, (iv) de um órgão de execução internacional que imponha aos Estados que praticarem condutas delituosas as sanções impostas pelo também inexistente "tribunal total mundial".

O complexo de normas costumeiras (direito internacional geral)

\footnotetext{
Em tempos de direito nacional primitivo, o que inexistia, na verdade, era especificamente o entendimento de que a imposição da sanção devia se dar pela intermediação de um órgão executor institucionalizado, fato esse que fez com que tal órgão executor não se fizesse presente.
} 
ou convencionais (direito internacional particular) parece positivar-se só e tão somente pelas somas dos costumes e pelas vontades específicas dos Estados, sendo o que se depreende do ensinamento do jusfilósofo argentino Ricardo Guibourg ${ }^{2}$ que, apesar de se referir somente à formação do direito costumeiro internacional, só podia ter também em mente a produção normativa internacional por tratados.

No direito interno, verifica-se o processo legislativo de produção normativa geral e abstrata, não havendo tal processo institucionalizado no plano internacional, visando à produção de normas de direito das gentes; denota-se em tais dizeres aquele primitivismo aludido por Kelsen, pois, classicamente, as normas de direito das gentes parecem ser criadas pelos próprios sujeitos de direito internacional e aplicadas pelos mesmos, dependendo eles, os sujeitos de direito internacional, para a aplicação da sanção internacional, única e exclusivamente de suas vontades, ao passo que no complexo estadual se verifica (a) a criação escalonada de normas por agentes autorizados do Estado, (b) o julgamento dos delitos e a dicção do direito - iuris dictio - pelas autoridades judiciárias competentes e (c) a aplicação da sanção pelo órgão estatal pré-determinado. E quando foi dito, linhas acima, que o direito internacional é criado pelas práticas reiteradas dos Estados e pelas manifestações de vontade dos mesmos, pode-se incluir o entendimento de que, principalmente no que diz respeito aos tratados, o consentimento dos Estados se faz necessário, pois, como ensina Francisco Rezek, ${ }^{3}$

No estágio presente das relações internacionais, é inconcebível que uma norma jurídica se imponha ao Estado soberano e à sua revelia. Para todo Estado, o direito das gentes é o acervo normativo que, no plano internacional, tenha feito objeto de seu consentimento, sob qualquer forma.

Se, por um lado, não há como se fechar os olhos ao caráter internacional da sociedade de nossos dias, por outro é de se notar a inafastável necessidade de os Estados soberanos criarem instituições e foros coletivos a fim de que seus problemas tenham tratamento que faça afastar o "primitivismo" do direito internacional, pois, como ensina Dalmo de

\footnotetext{
2 GUIBOURG. Derecho, Sistema y Realidad, p. 24: "(...) las normas consuetudinárias del derecho internacional dependen - según parece - de la voluntad concurrente de los Estados (o, al menos, de aquellos que tienen importancia decisiva en el concierto mundial)."

3 REZEK. Direito Internacional Público: Curso Elementar, p. 77.
} 
Abreu Dallari, ${ }^{4}$

(...) tecnicamente, os Estados vivem em situação de anarquia, pois embora exista uma ordem jurídica em que todos se integram, não existe um órgão superior de poder, a que todos se submetam. Este aspecto, aliás, já foi percebido no começo deste século, e pelo reconhecimento dessa deficiência é que, nos últimos tempos, têm sido criadas muitas organizações internacionais dotadas de órgão de poder. Esta é uma inovação importante, que modifica profundamente os termos do relacionamento entre os Estados.

Os dizeres de Dalmo de Abreu Dallari transcritos acima fornecem, com precisão, os rumos que o direito internacional deve seguir nos próximos tempos, rumos esses que já são verificáveis em vista do enorme número de organizações internacionais que existem desde a criação da Liga das Nações.

Com a evidente internacionalização que vem ocorrendo e ligando pessoas de diferentes nacionalidades e constantes trocas comerciais e de tecnologia, pode-se profetizar que o futuro do direito internacional está centrado nos tratados e nas organizações internacionais, principalmente pelo fato de que os dois institutos acabam se fundindo em atos de concepção consubstanciados no tratado-fundação que cria o organismo transnacional.

Só com o advento de organizações internacionais voltadas à mundialização se poderá manter a perspectiva de se ver uma comunidade centrada na isonomia, de Estados iguais em direitos e deveres, sem que um se sobreponha ao outro, contexto esse que já é verificável na União Européia e em seu direito comunitário.

O que se busca aqui neste artigo é passar o entendimento de que o complexo jurídico internacional, mesmo que não dotado dos órgãos legislativos, judiciais e de execução verificáveis no direito doméstico, já é portador de inegável poder coercitivo, poder este que se efetivará com muito maior eficácia na hipótese de se confirmar a multiplicação de organizações internacionais amplas e de tratados definidores de condutas a serem observadas.

No que diz respeito às organizações internacionais, ${ }^{5} \mathrm{o}$ desenvolvimento do direito das gentes foi tão acentuado na última década que tais organismos passaram a ser considerados, ao lado dos Estados, como

\footnotetext{
DALLARI. Elementos de Teoria Geral do Estado, p. 264.

5 A multiplicação das Organizações Internacionais tem propiciado uma verdadeira revolução na conquista além-fronteiras dos direitos humanos, pois é no seio destas Organizações que se constituem Comissões
} 
pessoas de direito internacional, ou seja, eles passaram a ser detentores de personalidade jurídica de direito das gentes, fato esse que se deve pioneiramente à disposição contida na Constituição da Organização Internacional do Trabalho - OIT $^{6}$-, de 1919.

Desde o reconhecimento das organizações internacionais como pessoas de direito internacional público, as mesmas têm podido celebrar tratados em seus próprios nomes.

Quanto à abrangência das organizações internacionais, Francisco Rezek $^{7}$ assim classifica:

- alcance universal, finalidade política (Rezek exemplifica com a Sociedade das Nações e a Organização das Nações Unidas);

- alcance universal, finalidade técnica específica (cita como exemplos as agências especializadas da ONU: a já citada Organização Internacional do Trabalho, a Organização das Nações Unidas para a Educação, a Ciência e a Cultura - UNESCO, o Fundo Monetário Internacional - FMI, etc.);

- alcance regional, finalidade política (exemplificando: Organização dos Estados Americanos - OEA, Liga dos Estados Árabes - LEA);

- alcance regional, finalidade técnica específica (Comunidade Econômica Européia - CEE, Associação Latino-Americana de Integração - ALADI, Acordo de Livre Comércio da América do Norte - NAFTA, etc.).

Mesmo que o desenvolvimento evolutivo das organizações internacionais se tenha dado de forma fragmentada, pode-se notar os traços característicos elencados por Marcus Rector Toledo Silva, ${ }^{8}$ quais sejam: "multilateralidade, permanência e institucionalização". Traduzindo a essência existencial de tais traços, temos que a multilateralidade se explica pelo fato

e Cortes que pautam suas atuações pela defesa das garantias fundamentais, tendo poderes investigatórios e jurisdicionais, na medida do consentimento dos Estados. Antônio Augusto Cançado Trindade dá conta do desenvolvimento dos instrumentos de proteção aos direitos humanos nas Organizações Internacionais: "(...) é alentador verificar que a prática da Comissão Interamericana de Direitos Humanos nesse particular (supra), mesmo antes da entrada em vigor da Convenção Americana sobre Direitos Humanos em nosso continente, coaduna-se com as experiências paralelas da Comissão Européia de Direitos Humanos (sob a Convenção Européia) e da Comissão de Direitos Humanos da ONU (sob o sistema da resolução 1.503 do ECOSOC), apontando todas no sentido de facilitar gradualmente o acesso dos particulares lesados às instâncias internacionais, e oferecer assim sua posição no plano internacional, em experimentos providos seja de base convencional, seja de base originalmente fornecida por instrumentos tecnicamente não obrigatórios (resoluções de organismos internacionais), mas que nem por isso deixam de exercer efeitos jurídicos em relação aos Estados-membros". CANÇADO TRINDADE. Direito das Organizações Internacionais, p. 639.

6 Organização Internacional do Trabalho - OIT, Constituição, artigo 19: "a organização internacional do trabalho deve possuir personalidade jurídica; ela tem, especialmente, capacidade (a) de contratar, (b) de adquirir bens móveis e imóveis, e de dispor desses bens, (c) de estar em juízo".

7 REZEK. Direito Internacional Público: Curso Elementar, p. 255-260.

8 SILVA. Mercosul e Personalidade Jurídica Internacional: as Relações Externas do Bloco Sub-regional PósOuro Preto, p. 9 
das organizações internacionais serem instituídas juridicamente, com personalidade de direito internacional público, por intermédio de tratados celebrados por vários Estados soberanos, enquanto a característica da permanência se explica pelo desejo de que estas organizações internacionais, ao serem criadas, tenham longevidade e, por último, a institucionalização é o processo de burocratização personificada que deve ser inerente à condição de organização internacional detentora do direito de produzir tratados e de veicular normas.

Aliás, no que atine à veiculação de normas, é este exatamente o ponto que está sendo tratado neste artigo, ou seja, a existência de normas jurídicas válidas e dotadas de eficácia no complexo jurídico internacional.

Não tem consistência lógica o temor de que a mundialização institucionalizada do direito internacional público propicie a institucionalização do poder do Estado mais forte sobre o mais fraco, do mais rico sobre o mais pobre, do mais politizado sobre o menos. A ocorrência de tal sobreposição é uma pressuposição que foge dos domínios do sistema jurídico, o que não nos impede de fazer a seguinte comparação metafórica: no ordenamento nacional do Estado moderno, todos os indivíduos devem se respeitar, não podem se maltratar, estão obrigados a observar os limites da propriedade privada etc. Contudo, mesmo assim as pessoas se desrespeitam, maltratam-se e ultrapassam os limites da propriedade privada. Mas ainda assim, subsiste o direito interno com as suas prescrições; e continuará existindo. Logo, se é verdade que o delito ocorre no âmbito interno, e mesmo assim se verifica coexistente o direito local, então também é verdade que o delito ocorre no âmbito externo, e mesmo assim se verifica coexistente o direito internacional.

Para que se evite que na mundialização vincenda se produzam normas internacionais que, por baixo da capa, sirvam somente aos interesses dos mais fortes, há que se intensificar o entendimento de que o consentimento dos Estados é conditio sine qua non para a veiculação de normas por tratados, como pensa Rezek. Pergunta-se: mas e se o Estado mais robusto forçar o consentimento do mais fraco? Em resposta, lançamos outra pergunta: mas e se o inquilino assinar o contrato por ter sido forçado pelo proprietário? Com as perguntas trocadas, infere-se: num trabalho jurídico, não cabe ao autor analisar temores que tenham sede meramente psicológica.

\section{Referências}

CANÇADO TRINDADE, Antônio Augusto. Direito das Organizações Internacionais. 2. ed.

A \& C R. de Dir. Administrativo e Constitucional, Belo Horizonte, ano 6, n. 23, p. 101-107, jan./mar. 2006 
Belo Horizonte: Del Rey, 2002.

DALLARI, Dalmo de Abreu. Elementos de Teoria Geral do Estado. 22. ed. São Paulo: Saraiva, 2001.

GUIBOURG, Ricardo A. Derecho, Sistema y Realidad. Buenos Aires: Editorial Astrea, 1986. REZEK, J. Francisco. Direito Internacional Público: Curso Elementar. 8. ed. São Paulo: Saraiva, 2000 .

SILVA, Marcus Rector Toledo. Mercosul e Personalidade Jurídica Internacional: as Relações Externas do Bloco Sub-regional Pós-Ouro Preto. Rio de Janeiro: Renovar, 1999.

Informação bibliográfica deste texto, conforme a NBR 6023:2002 da Associação Brasileira de Normas Técnicas (ABNT):

PAGLIARINI, Alexandre Coutinho. Teoria geral da ordem jurídica internacional. A\&C Revista de Direito Administrativo e Constitucional, Belo Horizonte, ano 6, n. 23, p. 101-107, jan./ mar. 2006 